\title{
ANALISIS SUSUT DAYA DAN ENERGI PADA JARINGAN DISTRIBUSI DI PT. PLN (Persero) RAYON PANAKKUKANG
}

\begin{abstract}
Analisis Susut Daya dan Energi Pada Jaringan Distribusi di PT. PLN (Persero) Rayon Panakkukang dengan rumusan masalah, berapa besar susut daya dan energy yang hilang pada penghantar jaringan distribusi Penyulang Perumnas di PT. PLN (Persero) Rayon Panakkukang dan berapa besar biaya yang hilang yang ditanggung oleh PLN. Sistem distribusi merupakan bagian dari sistem tenaga listrik, dimana berguna untuk menyalurkan tenaga listrik dari sumber daya listrik besar (Bulk Power Source) sampai ke konsumen.Penelitian ini bertujuan untuk menghitung besar susut daya dan energi yang hilang pada penghantar jaringan distribusi Penyulang Perumnas serta mengetahui perkiraan besar kerugian yang ditanggung oleh PLN pada Penyulang Perumnas.Metode yang digunakan dalam penelitian ini yakni untuk data primer dengan metode observasi,, metode wawancara, dan untuk data sekunder yakni menggunakan metode literatur. Setelah data-data dikumpulkan maka selanjutnya diolah dengan menganalisis menggunakan persamaan yang ada. Ladasan teori yang digunakan adalah Rugi Daya, teori Perhitungan Rugi-Rugi Daya (Losses) dan Rugi Energi serta Perkiraan Kerugian Dana.Berdasarkan analisa data yang telah dilakukan pada 30 unit transformator distribusi pada Penyulang Perumnas dapat disimpulkan bahwa terjadi Penyusutan Daya sebesar 4,806.70 kW dan Rugi Energi sebesar 720,974,174.6 Wh yang disebabkan oleh besarnya arus yang diterima transformator pada ssaat beroperasi.Dengan penggantian kapasitor transformator yang sesuai dengan standar yang berlaku akan meminimalisir terjadinya hal tersebut
\end{abstract}

Keywords: Susut Daya, Susut Energi, Kerugian Akibat Susut Daya, Penyulang Transformator Distribusi.

\section{PENDAHULUAN}

Kemajuan ilmu pengetahuan dan teknologi di jaman sekarang membuat kebutuhan energi listrik semakin meningkat dikalangan masyarakat. Laju pertumbuhan penduduk yang terus meningkat berbanding lurus dengan peningkatan kebutuhan energi listrik setiap tahun. Hal inilah yang memunculkan masalah baru bagi perusahaan listrik negara (PLN). Sumber energi listrik yang disalurkan oleh PLN tidak semuanya dapat diterima oleh konsumen karena sebagian ada yang hilang dalam bentuk susut daya (losses). Penyebab susut daya (losses) bisa diakibatkan oleh beberapa faktor antara lain yaitu kebocoran isolator akibat penurunan tegangan, kelebihan beban. Penurunan tegangan merupakan indikator utama dalam kualitas daya dan memiliki pengaruh besar pada keadaan normal peralatan listrik.

\section{KAJIAN LITERATUR}

A. Sistem Distribusi Tenaga Listrik

Sistem distribusi merupakan bagian dari sistem tenaga listrik. Sistem distribusi ini berguna untuk menyalurkan tenaga listrik dari sumber daya listrik besar (bulk power source) sampai ke konsumen. Energi listrik dibangkitkan pada pembangkit listrik seperti PLTU, PLTA, PLTG, PLTD maupun PLTN. Jenis pembangkit tenaga listrik yang digunakan pada umumnya tergantung dari jenis bahan bakar yang digunakan. Tenaga listrik yang dihasilkan oleh pembangkit tenaga listrik besar dengan tegangan dari $11 \mathrm{kV}$ sampai $24 \mathrm{kV}$ dinaikan tegangannya oleh Gardu Induk (GI) dengan transformator step-up menjadi $70 \mathrm{kV}, 154 \mathrm{kV}, 220 \mathrm{kV}$ atau $500 \mathrm{kV}$ kemudian disalurkan melalui saluran transmisi..

Pada umumnya, pembangkit tenaga listrik berada jauh dari pengguna tenaga listrik oleh karena itu energi listrik tersebut perlu di transmisikan melalui saluran transmisi. Untuk mentransmisikan energi listrik tersebut tegangannya harus dinaikkan dari tegangan menengah (TM) menjadi tegangan tinggi $70 / 150 \mathrm{kV}$ (TT) 
ataupun tegangan ekstra tinggi $500 \mathrm{kV}$ (TET). Tegangan yang lebih tinggi ini diperoleh dari transformator penaik tegangan (Step-up transformer). Pemakaian tegangan tinggi ini diperlukan untuk berbagai alasan efisiensi,antara lain, penggunaan penampang penghantar menjadi efisien, karena arus yang mengalir akan menjadi lebih kecil ketika tegangan tinggi diterapkan.

Dari saluran transmisi, tegangan diturunkan lagi menjadi $20 \mathrm{KV}$ dengan transformator penurun tegangan (stepdown transformer) pada gardu induk distribusi, kemudian dengan sistem tegangan tersebut penyaluran tenaga listrik dilakukan oleh saluran distribusi primer untuk disalurkan ke Transformator (GD) atau pemakai Tegangan Menengah (TM) untuk diturunkan tegangannya dengan transformator distribusi menjadi sistem Tegangan Rendah (TR), yaitu 220/380Volt. Selanjutnya disalurkan oleh saluran distribusi sekunder ke konsumen.

\section{B. Susut Daya}

Rugi daya adalah suatu bentuk kehilangan energi listrik yang berasal dari sejumlah energi listrik yang disediakan PLN dengan sejumlah energi yang terjual ke konsumen dan mengganggu efisiensi sistem distribusi listrik.

Jika suatu penghantar dialiri arus listrik secara terus-menerus akan menimbulkan panas yang timbul akibat adanya energi listrik yang mengalir pada penghantar tersebut dan menyebabkan kerugian pada daya listrik tersebut. Semakin lama arus tersebut mengalir maka semakin panas pulla penghantar dan semakin banyak pula energi listrik yang hilang. Hal inilah yang merugikan Karena jika energi hilang, maka tegangan pada ujung penghantar tersebut akan berkurang.

C. Perhitungan Rugi-Rugi (Losses) Daya
Rugi daya yang terjadi pada kawat penghantar suatu jaringan dapat dihitung dengan menggunakan persamaan :

$$
\Delta P=I^{2} \cdot Z \cdot L
$$

Dimana :

$\Delta P=$ Susut Daya (Watt)

$I^{2}=$ Arus yang disuplai dari Gardu

Induk (A)

$\mathrm{Z}=$ Impedansi $(\Omega / \mathrm{m})$

$\mathrm{L}=$ Panjang Saluran $(\mathrm{m})$

Untuk menghitung Rugi Daya Total menggunakan persamaan :

Dimana :

$$
\Delta P_{T o t}=\Delta P_{R}+\Delta P_{S}+\Delta P_{T}
$$

$\Delta P_{T o t}=$ Rugi Daya Total (Watt)

$\Delta P_{R} \quad=$ Rugi Daya Fasa $\mathrm{R}$

$\Delta P_{S} \quad=$ Rugi Daya Fasa $\mathrm{S}$

$\Delta P_{T} \quad=$ Rugi Daya Fasa $\mathrm{T}$

Tahanan ( $R$ ) dan reaktansi $\left(X_{L}\right)$ penghantar AAAC tegangan $20 \mathrm{kV}$ (SPLN 64: 1985)

\begin{tabular}{|c|c|c|c|c|c|}
\hline $\begin{array}{c}\text { Luas } \\
\text { Penampang } \\
\left(\mathrm{mm}^{2}\right)\end{array}$ & Jari ${ }^{2} \mathrm{~mm}$ & Urat & $\begin{array}{c}\text { GMR } \\
(\mathrm{mm})\end{array}$ & $\begin{array}{c}\text { Impedansi urutan positif } \\
(\text { Ohm } / \mathrm{km})\end{array}$ & $\begin{array}{c}\text { Impedansi urutan Nol } \\
(\text { Ohm } / \mathrm{km})\end{array}$ \\
\hline 16 & 2,2563 & 7 & 1,6380 & $2,0161+\mathrm{j} 0,4036$ & $2,1641+\mathrm{j} 1,6911$ \\
\hline 25 & 2,8203 & 7 & 2,0475 & $1,2903+\mathrm{j} 0,3895$ & $1,4384+\mathrm{j} 1,6770$ \\
\hline 35 & 3,3371 & 7 & 2,4227 & $0,9217+\mathrm{j} 0,3790$ & $1,0697+\mathrm{j} 1,6665$ \\
\hline 50 & 3,9886 & 7 & 2,8957 & $0,6452+\mathrm{j} 0,3678$ & $0,7932+\mathrm{j} 1,6553$ \\
\hline 70 & 4,7193 & 7 & 3,4262 & $0,4608+\mathrm{j} 03572$ & $0,6088+\mathrm{j} 1,6447$ \\
\hline 95 & 5,4979 & 19 & 4,1674 & $0,3096+\mathrm{j} 0,3449$ & $0,4876+\mathrm{j} 1,6324$ \\
\hline 120 & 6,1791 & 19 & 4,6837 & $0,2688+\mathrm{j} 0,3376$ & $0,4168+\mathrm{j} 1,6324$ \\
\hline 150 & 6,9084 & 19 & 5,2365 & $0,2162+\mathrm{j} 0,3305$ & $0,3631+\mathrm{j} 1,6180$ \\
\hline 185 & 7,6722 & 19 & 5,8155 & $0,1744+\mathrm{j} 0,3239$ & $0,3224+\mathrm{j} 1,6114$ \\
\hline 240 & 8,7386 & 19 & 6,6238 & $0,1344+\mathrm{j} 0,3158$ & $0,2824+\mathrm{j} 1,6034$ \\
\hline
\end{tabular}

D. Perhitungan Rugi Energi dan Perkiraan Kerugian Dana Akibat Rugi-Rugi Daya

Perusahaan pemasok listrik mengalami kerugian yang cukup besar setiap bulannya karena hilangnya energi akibat rugi-rugi daya. Besaran daya yang hilang saat proses pentransmisian harus dihitung dan diantisipasi, sehingga besar daya yang hilang masih dalam batas yang ditolelir (Nolki,et all, 2015). Setelah mengetahui rugi-rugi daya yang hilang maka dapat dilakukan perhitungan untuk mengetahui energi yang hilang.

Dimana :

$$
W=P_{t o t} \times t
$$

$\mathrm{W}=$ Rugi Energi listrik (Watt $\mathrm{jam} / \mathrm{Wh}$ )

$P_{\text {tot }}=$ Daya alat listrik (Watt) $\mathrm{t}=$ Lama pemakaian / puncak beban (jam) 
BiayaRugiDayaListrik=

$\left(\frac{W}{1000}\right) \times T D L$

Dimana :

$\left(\frac{W}{1000}\right)=$ Pemakaian listrik $(\mathrm{kWh})$

$\mathrm{TDL}=$ Tarif dasar listrik $(\mathrm{Rp} / \mathrm{kWh})$

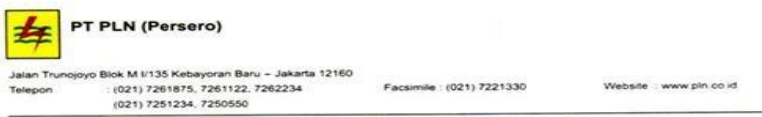

PENYESUAIAN TARIF TENAGETASTRN TRIK TARIFF ADJUSTMENT BULAN JANUARI - MARET 2019

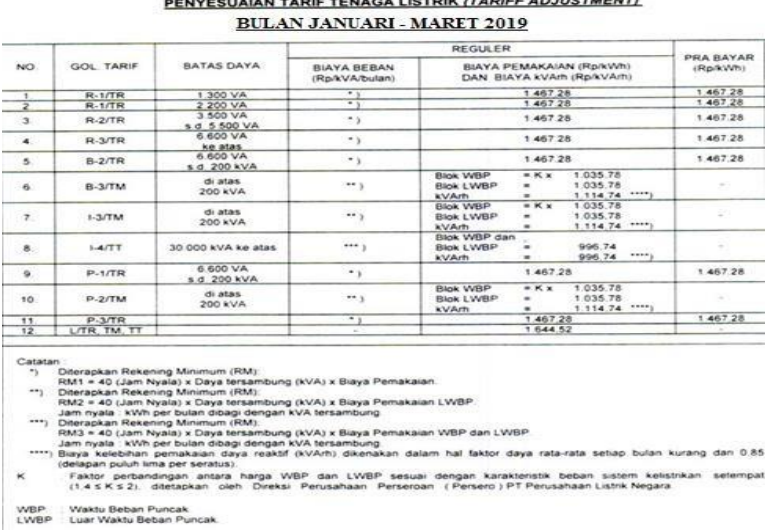

\section{E. METODE PENELITIAN}

A. Tempat dan Waktu Penelitian Penelitian ini dilaksanakan di PT.PLN (Persero) Area Makassar Rayon Panakukang, tempat ini merupakan sumber data bagi penulis.

Penelitian dan pengambilan data berlangsung selama 4 bulan yang dilaksanakan mulai pada bulan Februari Mei 2019.

\section{B. Prosedur Penelitian}

Prosedur kegiatan pada tugas akhir ini dimulai dengan melakukan survei lapangan, dengan melihat keadaan gardu distribusi yang akan dilakukan pengukuran. Kemudian mengambil data pada PT. PLN (Persero) rayon panakukang dan melakukan penelitian pada gardu distribusi.

C. Metode Pengumpulan data

1. Survei

Survei adalah melakukan kunjungan atau pengamatan langsung di PT. PLN (Persero) rayon panakukang, untuk mengetahui kondisi real dan mendapatkan data-data yang diperlukan dan informasi penting lainnya dalam penyusunan tugas akhir ini.

2. Wawancara
Metode pengumpulan data ini dilakukan dengan mengadakan tatap muka atau wawancara secara langsung dengan pimpinan perusahaan atau orang-orang yang mempunyai pengetahuan yang ada kaitannya dengan penyusunan tugas akhir ini.

\section{Observasi}

Obsevasi bertujuan mengamati perubahan dan hal-hal yang terjadi pada saat mengumpulkan data.

\section{Studi Literatur}

kegiatan ini dilakukan dengan mengadakan studi dari buku-buku/pustaka, situs-situs internet dan literatur lain yang berkaitan dengan masalah yang dibahas dalam penulisan skripsi ini.

D. Metode Analisis Data Pengumpulan data dilakukan dengan tiga metode yang dijelaskan sebelumnya.

\section{F. HASIL DAN PEMBAHASAN}

1. GT.PPR001

$$
\text { Fasa R }
$$

$$
\text { A. Rugi Daya }
$$

$$
\begin{aligned}
P= & I^{2} \cdot Z \cdot L \\
= & 6^{2} \cdot(0.6452+j 0.3678) \cdot 0.17 \\
= & 36 \cdot(0.109684+j 0.062526) \\
= & 3.948624+j 2.250936 \\
= & 4.545145<29.68^{\circ} \\
& \text { Fasa } \mathrm{S} \\
P= & I^{2} \cdot Z \cdot L \\
= & 16^{2} \cdot(0.6452+j 0.3678) \cdot 0.17 \\
= & 256 \cdot(0.109684+j 0.062526) \\
= & 28.079104+j 16.006656 \\
= & 32.321032<29.68^{\circ} \\
& \text { Fasa } \mathrm{T} \\
P= & I^{2} \cdot Z \cdot L \\
= & 32^{2} \cdot(0.6452+j 0.3678) \cdot 0.17 \\
= & 1024 \cdot(0.109684+j 0.062526) \\
= & 112.316416+j 64.026624 \\
= & 129.284129<29.68^{\circ}
\end{aligned}
$$

Daya Total

$$
\begin{aligned}
P_{\text {TOT }}= & P_{R}+P_{S}+P_{T} \\
& =4.545145+32.321032 \\
& \quad+129.284129 \\
= & 166.150306 \mathrm{~W} \\
= & 0.2 \mathrm{~kW}
\end{aligned}
$$

B. Rugi Energi

$W=P_{T O T} \cdot t$ 


$$
\begin{aligned}
& =166.150306 \cdot 5 \cdot 30 \\
& =166.150306 \cdot 150 \\
& =24922.5459 \mathrm{Wh}
\end{aligned}
$$

*keterangan :

$\mathrm{t}=5$ karena lama waktu beban puncak adalah selama 5 jam, mulai dari pukul $17.00-22.00$

$\mathrm{t}=30$ karena data tersebut merupakan data 1 bulan

C. Kerugian Dana Akibat Rugi-

\section{Rugi Daya}

$$
\begin{aligned}
R p & =\left(\frac{W}{1000}\right) \cdot T D L \\
& =\left(\frac{24922.5459}{1000}\right) \cdot 1467.28 \\
& =24.9225459 \cdot 1467.28 \\
& =R p 36,568.35
\end{aligned}
$$

Penyulang Perumnas menyuplai 30 unit transformator yang memiliki kapasitas yang berbeda-beda dimana hubungan arus pada trafo berbanding lurus dengan rugi daya dan energi yaitu, semakin besar arus yang mengalir pada trafo maka semakin besar pula rugi daya dan rugi energinya. Tentunya hal tersebut akan membuat harga kerugian akibat susut daya akan semakin besar pula.

\section{G. KESIMPULAN}

Berdasarkan analisa data yang telah dilakukan pada 30 unit transformator distribusi pada Penyulang Perumnas di Rayon Panakkukang, dengan hasil yang didapatkan maka dapat disimpulkan bahwa terjadi penyusutan daya sebesar $4806.70 \mathrm{~kW}$ dan rugi energi sebesar 721005000.00Wh yang disebabkan oleh besarnya arus yang diterima transformator disribusi pada saat beroperasi. Dimana semakin nilai arus, maka susut daya dan susut energinya juga akan semakin besar.

Seperti kesimpulan pada nomor 1 dimana semakin besar arus maka semakin besaar pula susut daya dan susut energinya begitupun pada besar kerugian yang ditanggung oleh PLN akibat terjadinya penyusutan tersebut sehingga daya yang disalurkan tidak dapat tersalur secara optimal dan menyebabkan kerugian sebesar Rp1,057,916,216.40 pada Penyulang tersebut.

\section{UCAPAN TERIMA KASIH}

Ucapan terima kasih ditujukan kepada :

1 Kedua orang tua atas segala doa, pengorbanan, motivasi, kasih sayang yang menjadi penggugah semangat penulis.
2. Dosen pembimbing 1 Ir. Talib Bini M.T. dan Dosen pembimbing 2 Purwito S.T.,M.T. 4. Staff PLN yang telah membantu dan menyediakan waktu luangnya dalam pengambilan data.

3. Teman-teman yang telah membantu dalam belajar.

\section{REFERENSI}

[1] Arismunandar, dan Artono. 2001. Teknik Tegangan Tinggi. Jakarta: Pradnya Paramita.

[2] IEEE. 1995. "Recommended Practice for Emergency and Standby Power System for Industrial and Commercial Application." IEEE Std 446 - 199553.

[3] Nasional, Badan Standarisasi. 2011. Persyaratan Umum Instalasi Listrik 2011. Jakarta: Badan Standarisasi Nasional.

[4] Setiadji, Julius Sentosa, Tabrani Machmudsyah, dan Yanuar Isnanto. 2006. "Pengaruh Ketidakseimbangan Beban Terhadap Arus Netral dan Losses pada Transformator Distribusi." Jurnal Teknik Elektro 6: 68-73.

[5] Simanora, Yoakim, Panusur, dan Tobing. 2014. "Analisis Ketidakseimbangan Beban Transformator Distribusi untuk Identifikasi Beban Lebih dan Estimasi Rugi-Rugi pada Jaringan Tegangan Rendah." Singuda Ensikom, 7 (2) 137 $-142$.

[6] Syarifuddin. 2012. Mesin Arus Searah dan Transformator. Makassar: Politeknik Negeri Ujung Pandang.

[7] Tamara, Verika. 2016. Pengaruh Pemerataan Beban Terhadap Rugi Rugi Jaringan Tegangan rendag Transformator Distribusi. Palembang: Politeknik Negeri Sriwijaya.

[8] Zuhal. 1991. Dasar Tenaga Listrik. Bandung: ITB.

[9] Khoiriyah, Siti. 2014 Analisis Susut Daya Dan Energi Pada Jaringan Distribusi Di Transformator Induk Beringin Penyulang BRG-4 Menggunakan Software ETAP12.6. Universitas Muhammadiyah Surakarta

[10] Al-Badi, A., A. Elmoudi, I. M., Al-Wahaibi, A., Al-Ajmi, H., \& Al-Bulushi, M. (2011). Losses 
Reduction in Distribution

Transformers. International Multi

Conference of Engineers and

Computer Sciences.

[11] Hontong, NJ, Maickel

Teugueh, Lily S.(2015). Analisa Rugi-

Rugi Daya Pada Jaringan Distribusi di

PT.PLN Palu, Universitas Sam

Ratulangi Manado.

http://jurnal.untirta.ac.id/index.php/V

OLT/article/view/816

[12] Pabla, A.S.(1991). System

distribusi daya listrik. Jakarta:

Penerbit Erlangga

[13] Sarang Pande and Prof. J.G.

Ghodekar, (2012). Computation of

Technical Power Loss of Feeders and

Transformers in Distribution System

using Load Factor and Load Loss

Factor, International Journal of

Multidisciplinary Sciences and

Engineering.

[14] Vujosevic, L. Spahic E. and

Rakocevic D., "One Method for the

Estimation of voltage drop in

Distribution System",

http://www.docstoc.com/document/

education, March, 2011

[15] Siti Khoiriyah, "Analisa Susut

Daya dan Energi Pada Jaringan

Distribusi Di Transformator Induk

Beringin Penyulang BRG-4

Menggunakan Software ETAP 12.6",

http://eprints.ums.ac.id/60918/4/cek\%

20siti.pdf

[16]Muhammad Ridwan, "Analisis Rugi

Daya Jaringan Tegangan Rendah

Akibat Ketidakseimbangan Beban

Transformator Distribusi PT. PLN

(Persero) Rayon Panakkukang" 